Journal of Bangladesh Academy of Sciences, Vol. 36, No. 2, 241-250, 2012

\title{
SOURCE IDENTIFICATION OF CARBONACEOUS AEROSOLS DURING WINTER MONTHS IN THE DHAKA CITY
}

\author{
BILKIS A. BEGUM ${ }^{*}$, KOLLOL ROY ${ }^{1}$, FAKRUL ISLAM $^{1}$, A. SALAM ${ }^{1}$ \\ AND PHILIP K. HOPKE ${ }^{2}$
}

Chemistry Division, Atomic Energy Centre, P.O. Box-164, Dhaka, Bangladesh

\begin{abstract}
Air particulate matter samples were collected using Air Metrics samplers from 11 - 17 January and 19 - 27 January, 2012 at Amin Bazar and Farm Gate sites, respectively. The sampling time was from 8 a.m. - 4 p.m. Three samplers were used of which two samplers were for $\mathrm{PM}_{2.5}$ samples, using Teflon and quartz filters and the others for $\mathrm{PM}_{10}$ samples using Teflon filter. Organic and elemental carbons (OC and $\mathrm{EC}$ ) were measured in $\mathrm{PM}_{2.5}$ samples at both sites. It has been found that the EC concentration at Amin Bazar is higher than in Farm Gate. The contribution of EC may come from diesel, gasoline and coal/wood combustions in the Amin Bazar site. The present OC/EC data were compared with the previous data. It was found that the concentration of EC became higher than those in the previous year. During last couple of years, Government implemented different policies specially in case of motor vehicles to improve the air quality. But due to the use of diesel in quick rental power plants, the air quality start to deteriorate. BC plays an important role to change the climate. Hence, government should think of alternatives to meet the power demand in place of diesel.
\end{abstract}

Key words: Source identification, Carbonaceous aerosols, Winter months

\section{INTRODUCTION}

Ambient particulate matter (PM), specially in urban and highly industrialized areas, contains an important fraction of carbonaceous materials (Cao et al. 2006, Dan et al. 2004, Meng et al. 2007). Atmospheric particulate carbon is comprised of a complex mixture of substances containing carbon atoms, in two fractions; organic carbon (OC) and elemental carbon (EC). EC is mainly emitted from anthropogenic combustion sources and does not undergo chemical transformations. It is used as a good indicator of primary anthropogenic air pollutants (Kim and Henry 2000, Lin and Tai 2001). OC, containing PAHs, PCBs and other components with potential mutagenic and carcinogenic effects, has both a primary and secondary origin (Ram et al. 2008). Primary organic carbon (POC) is formed during combustion and emitted in particulate form, while

\footnotetext{
* Author for correspondence: <bilkisab@dhaka.net>

${ }^{1}$ Department of Chemistry, Dhaka University, Dhaka-1000, Bangladesh.

${ }^{2}$ Centre for Air Resource and Engineering Science, Clarkson University, NY, USA.
} 
secondary organic carbon (SOC) is formed in the atmosphere through gas-to-particle conversion processes of volatile organic compounds either as a result of the condensation of low vapor pressure volatile organics or chemical adsorption of gaseous species on aerosol particle surfaces (Pankow 1994, Turpin and Huntzicker 1995). Formation of SOC has frequently been observed during laboratory investigations in smog chamber experiments from light irradiation of gaseous mixtures containing organic compounds (Pankow 1994, Stern et al. 1987).

Rapid industrialization and economic development occurred in Dhaka during recent years and may increase the emission of various pollutants. Lack of extensive and effective pollution control measurement means that the amount of particulate matter emitted into atmosphere will increase and impact on climate, agriculture and health of the public. Many studies have been performed in the world focusing on carbonaceous species of PM but only limited studies have been done in Dhaka. Dhaka is considered as one of the most developed cities of Bangladesh and high PM levels and poor visibility in winter time have become a serious problem. Coal and biomass burning in the brick field, vehicle exhaust, and industrial and residential emission during the power cut all contribute to the ambient PM in the city. On the other hand, due to the meteorological reason, there is also transboundary transport during the winter time. The government has taken various policy measures in order to reduce the carbonaceous materials as well as particulate matters (PM) in the air. Therefore, the observations for OC and EC analysis are needed for Dhaka city to observe the change of carbonaceous particles in the air.

In this paper, the concentration and sources of carbonaceous particles are presented and compared with the previous results. The work is aimed to quantify the contribution of carbonaceous species to $\mathrm{PM}_{2.5}$, identify the potential sources of carbonaceous particles and meteorological influences during sampling period. Information obtained in this study will also allow evaluation of the changes in the air quality compared to the previous years in Dhaka city and help to develop further pollution control strategies for particulate matters.

\section{MATERIALS AND METHODS}

The measurements were carried out at an urban site at Dhaka. PM samplings were performed using Air Metrics MiniVol sampler for collecting $\mathrm{PM}_{2.5}$ samples from Amin

Bazar and Farm Gate, (latitude: $23.76^{\circ} \mathrm{N}$; longitude: $90.39^{\circ} \mathrm{E}$ ) continuous air monitoring station (CAMS-2) site (Fig. 1) in Dhaka city. Amin Bazar is a hot spot site having a large bus station connecting to the northern districts of Bangladesh. There are also brickfields cluster and boats driven by residual oil. A large number of heavy duty vehicles, which bring raw food materials to Dhaka from the northern districts. On the other hand, Farm 
Gate is a also hot spot site due to the proximity of several major roadways intersection and large numbers of vehicles plying through the area (Begum et al. 2005). The site is in the mixed area (i.e., commercial and semi-industrial area). The Tejgaon industrial area is very near to the site.

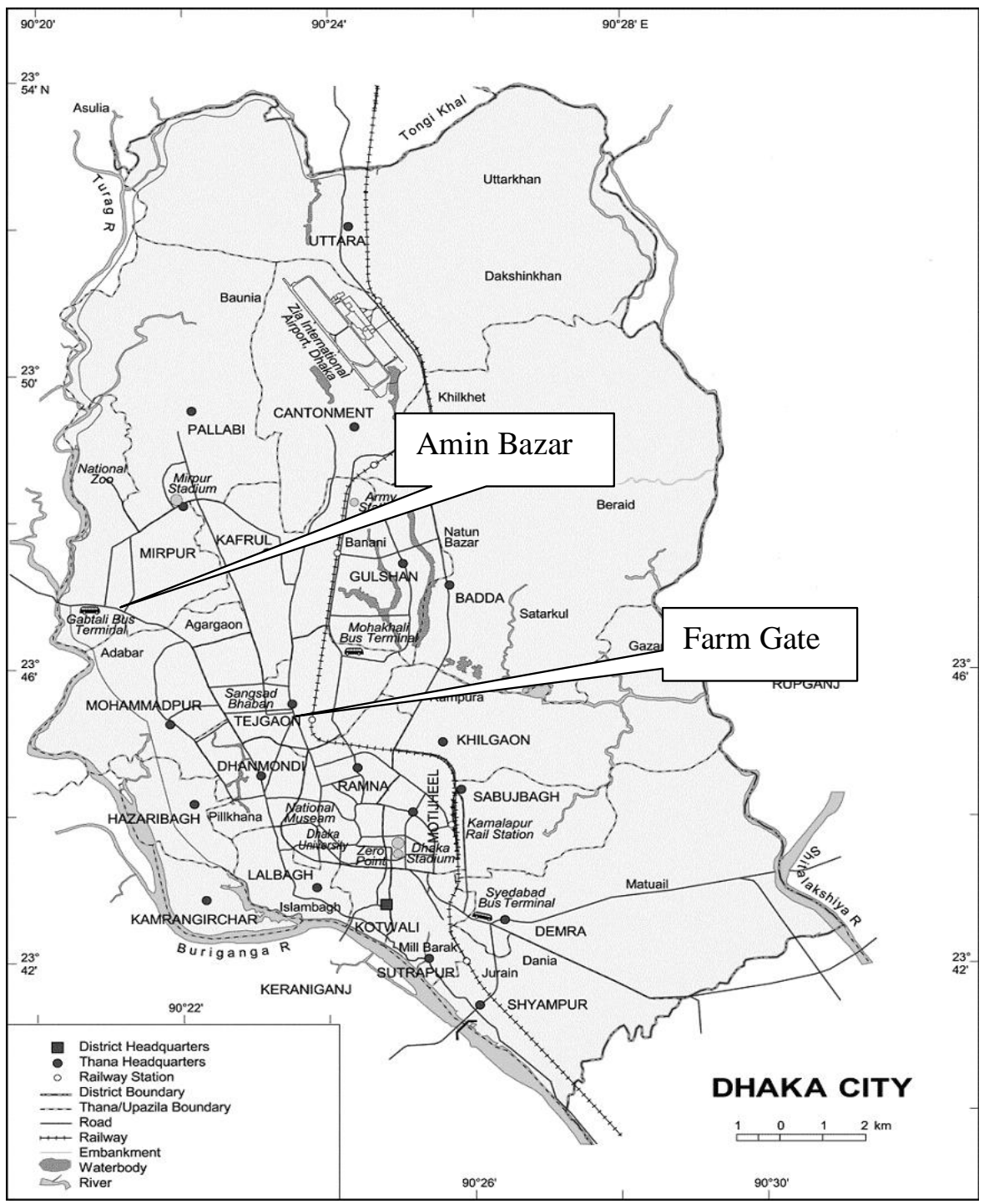

Fig. 1. Map of sampling locations in Dhaka city.

The Air Metrics MiniVol sampler, developed jointly by the U.S. Environmental Protection Agency (EPA) and the Lane Regional Air Pollution Authority, was used for 
both $\mathrm{PM}_{10}$ and $\mathrm{PM}_{2.5}$ sampling (Baldauf et al. 2001). At Farm Gate, the samplers were placed on the flat roof of the guardhouse of Bangladesh Agricultural Research Council (BARC). This location is also used as the second continuous air monitoring station (CAMS-2) at Dhaka. The MiniVols were programmed to sample at $5 \mathrm{lpm}$ through $\mathrm{PM}_{2.5}$ particle size separator (impactor) and then through $2 \mu \mathrm{m}$ pore Teflon and quartz filters. The actual flow rate should be $5 \mathrm{lpm}$ at ambient conditions for proper size fractionation. To ensure a constant flow of $5 \mathrm{lpm}$ through the size separator at different air temperatures and ambient pressures, the sampler flow rates were adjusted for the ambient conditions at the sampling site. The MiniVol sampler was positioned with the intake upward and located in an unobstructed area at least $30 \mathrm{~cm}$ from any obstacle to air flow and the sampler inlet was placed at a height of $10 \mathrm{~m}$ above the ground level for the Farm Gate area. The intake nozzle of the sampler at the Farm Gate location was about $5 \mathrm{~m}$ away from the main road. Two samples of $\mathrm{PM}_{2.5}$ were simultaneously collected on Teflon and quartz filters for $24 \mathrm{hr}$ with two MiniVol samplers. The inlets of the samplers were kept $45 \mathrm{~cm}$ apart from each other.

The samplings were done at Amin Bazar site from January 10 - 17 and at Farm gate site from January 19 - 27. The samples were collected for $8 \mathrm{hr}$ from 8 a.m. to 4 p.m. in both sites. The conditioned clean filters were loaded in their respective filter holder assembly at the CAMS-2 conditioning room and were brought to sampling site in separate, clean polyethylene bags on each effective sampling day. After sampling, the filter holder assemblies (keeping the exposed filters inside) were brought to the conditioning room of Atomic Energy Centre, Dhaka (AEC,D) directly from the sampling site for conditioning and PM mass measurement. Care was taken in transporting the exposed filter holder assemblies, so that there should be no PM loss. The loaded quartz filters were kept in freeze at $4^{\circ} \mathrm{C}$ until chemical analysis to limit losses of volatile components. To reduce the carbonaceous species background level in the filter, quartz filters were pretreated at $900^{\circ} \mathrm{C}$ for $180 \mathrm{~min}$ and then placed in clean polyethylene Petri dishes. The Petri dishes were then wrapped with Teflon tape and aluminum foil and stored in a freezer until field measurement.

The samples were analyzed for OC/EC using DRI Model 2001 (Thermal/Optical Carbon Analyzer). The IMPROVE A thermal/optional reflectance (TOR) protocol was used for the carbon analysis. The analyzer was calibrated using $5 \% \mathrm{CO}_{2}$ in helium. The regression (Amount of calculated carbon from $5 \% \mathrm{CO}_{2}$ and peak area ratio between standard $\mathrm{CO}_{2}$ peak area and internal standard methane peak area) slope and coefficient is slope $=20.592, \mathrm{R}^{2}=0.998$. The protocol heats a $0.526 \mathrm{~cm}^{2}$ punch aliquot of a sample quartz filter stepwise at $140^{\circ} \mathrm{C}(\mathrm{OC} 1), 280^{\circ} \mathrm{C}(\mathrm{OC} 2), 480^{\circ} \mathrm{C}(\mathrm{OC} 3)$ and $580^{\circ} \mathrm{C}(\mathrm{OC} 4)$ in a non-helium $(\mathrm{He})$ atmosphere and $580^{\circ} \mathrm{C}(\mathrm{EC} 1), 740^{\circ} \mathrm{C}(\mathrm{EC} 2)$ and $840^{\circ} \mathrm{C}(\mathrm{EC} 3)$ in an 
oxidizing atmosphere of $2 \%$ oxygen in a balance of helium. The carbon that evolves at each temperature is oxidized to carbon dioxide $\left(\mathrm{CO}_{2}\right)$ and then reduced to methane $(\mathrm{CH} 4)$ for quantification with a flame ionization detector. As temperature increases in the inert helium, some of the organic carbon pyrolyzes to elemental carbon, resulting in darking of the filter deposit. This darkening is monitored by reflectance of $633 \mathrm{~nm}$ light of a He-Ne laser. When oxygen is added, the original and pyrolyzed elemental carbon combusts and the reflectance increase. The amount of the carbon measured after oxygen is added until the reflectance achieves its original value is reported as optically detected pylolyzed carbon (OPC). The seven fractions OC1, OC2, OC3, OC4, EC1, EC2 and EC3 are reported in Figs 2 and 3. The IMPROVE protocol defines OC as OC1+OC2+OC3+OC4 and $\mathrm{EC}$ as $\mathrm{EC} 1+\mathrm{EC} 2+\mathrm{EC} 3$. The analyzer was calibrated with known quantities of $\mathrm{CH}_{4}$ everyday and the reproducibility of calibration is $24126 \pm 268$. Replicate analyses were performed at the rate of one per group of 8 samples. Blank filters were also processed, similar to the protocol used for samples, in order to assess the analytical detection limits. The detection limit (for TC) is $<3 \mu \mathrm{g}$ carbon $/ \mathrm{cm}^{2}$ where TC is total carbon. Concentrations of carbonaceous species in the blanks were below the detection limits (TC $=0.85 \square \mathrm{g}$ carbon $/ \mathrm{cm}^{2}$ ) in the present analysis. In order to check data value, EC data were compared with the co-located $\mathrm{PM}_{2.5}$ samples where Teflon filters were used for fine particulate matter collection. The $\mathrm{BC}$ in $\mathrm{PM}_{2.5}$ was determined using reflectometer and compared with EC on quartz, which was measured with carbon analyzer. The regression slope and coefficient is slope $=1.04, \mathrm{R}^{2}=0.993$.

The process of identification and apportionment of pollutants to their sources is an important step in air quality management. Principal component analysis (PCA) (Hopke 1985) used measurements of pollutant concentrations at a sampling site to identify significantly correlated variables. This method extracts components explaining the majority of variance of the data matrix which was then qualitatively interpreted as possible sources (Hopke 1985, Hopke et al. 1976, Wolff et al. 1985). PCA is often useful to provide information regarding source characteristics in terms of the elements that are associated with a given source type. These methods are based on the analysis of the correlation between measured concentrations of chemical species, assuming that highly correlated compounds are emitted from the same source.

\section{RESULTS AND DISCUSSION}

A summary of the results for $8 \mathrm{hr}$ average concentrations of EC TC, and EC/TC from two sites of Dhaka are given in Table 1. It has been found that the average ratio of EC/TC at Amin Bazar and Farm Gate sites are 0.56 and 0.43 , respectively. 
Table 1. Concentration of carbonaceous components $\left(\mu \mathrm{g} / \mathrm{m}^{3}\right)$.

\begin{tabular}{cllllllll}
\hline \multirow{2}{*}{ Date } & \multicolumn{3}{c}{ Amin Bazar site } & \multirow{2}{*}{ Date } & \multicolumn{3}{c}{ Farm Gate site } \\
\cline { 2 - 4 } & EC & TC & EC/TC & & EC & TC & EC/TC \\
\hline $1 / 11 / 2012$ & 48.7 & 82.9 & 0.59 & $1 / 19 / 2012$ & 17.6 & 40.1 & 0.44 \\
$1 / 12 / 2012$ & 34.5 & 61.3 & 0.56 & $1 / 20 / 2012$ & 16.1 & 41.7 & 0.39 \\
$1 / 13 / 2012$ & 28.5 & 55.9 & 0.51 & $1 / 21 / 2012$ & 28.9 & 69.3 & 0.42 \\
$1 / 14 / 2012$ & 55.2 & 95.1 & 0.58 & $1 / 22 / 2012$ & 23.7 & 57.3 & 0.41 \\
$1 / 15 / 2012$ & 45.7 & 78.6 & 0.58 & $1 / 23 / 2012$ & 24.4 & 52.9 & 0.46 \\
$1 / 16 / 2012$ & 41.8 & 79.6 & 0.52 & $1 / 24 / 2012$ & 32.1 & 70.6 & 0.45 \\
$1 / 17 / 2012$ & 42.5 & 72.8 & 0.58 & $1 / 25 / 2012$ & 30.0 & 61.9 & 0.48 \\
& & & & $1 / 27 / 2012$ & 21.1 & 53.8 & 0.39 \\
\hline
\end{tabular}

The reason for higher ratio of EC/TC at Amin Bazar site is due to high contribution of EC fractions (Fig. 2), which mainly comes from gasoline (signature of EC1), diesel (Signature of EC2 and EC3) and coal combustions (Signature of OC2). Principal component analysis (PCA) had been applied for source analysis in many studies (Cao et al. 2005, Li et al. 2010,Wang et al. 2010).

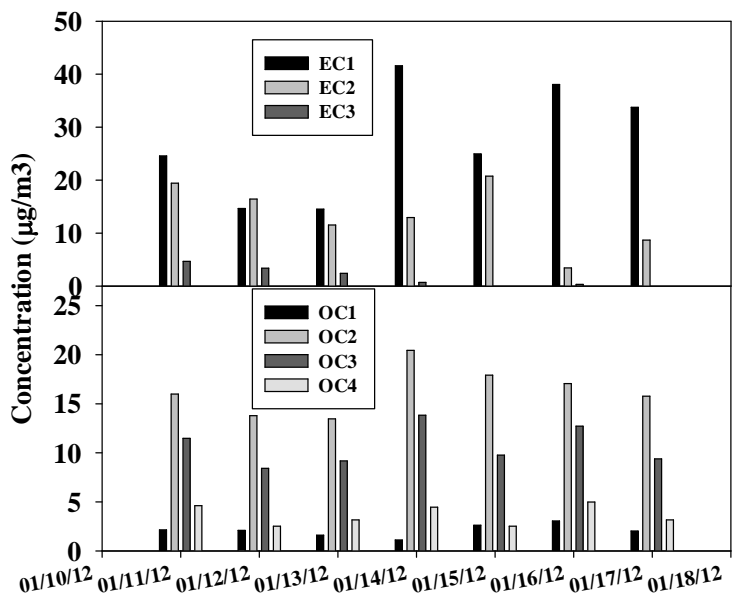

Fig. 2. Fractions of $\mathrm{OC} 1, \mathrm{OC} 2, \mathrm{OC} 3, \mathrm{OC} 4, \mathrm{EC} 1, \mathrm{EC} 2$ and $\mathrm{EC} 3$ in $\mathrm{PM}_{2.5}$ mass during the present study at Amin Bazar site.

In order to obtain reliable estimates of the different sources contributing to the fine mass measured at Amin Bazar site, Principal Components Analysis (PCA) was used to identify major elements associated with sources. Table 2 shows the factor loadings from the PCA analysis. Factors with two or more elements have factor loadings above 0.3 , have been highlighted. Four factors were required to explain $99 \%$ of the sample variance in case of fine particulate matter. Factor loadings near 1.0 demonstrate that the element has a strong association with that individual factor. For $\mathrm{PM}_{2.5}$ samples, four factors accounted for $49.4 \%$ of the variance, showed high loading for OC2, OC3, OC4 and EC1 and considered as marker for gasoline and road dust (Factor 1). OC4 and EC3 are considered as marker for CNG mixed with road dust (Factor 2). 
Factor 3 is enriched with OC2 and EC2, which explained $13.5 \%$ of variance is enriched in diesel exhaust. Factor 4, which explained $11.8 \%$ of the variance, has high loading for OC1 is enriched in biomass burning. This biomass burning contribution may come from both indoor air and as well as brick field. Because still now, wood is being used for brick burning in the kiln.

Table 2. Principal component analysis with varimax rotation for all $\mathbf{P M}_{2.5}$ data collected from Amin Bazar site.

\begin{tabular}{lcllc}
\hline \multirow{3}{*}{ Parameter } & \multicolumn{4}{c}{ Sources } \\
\cline { 2 - 5 } & $\begin{array}{c}\text { Factor 1 Gasoline } \\
\text { and Road dust }\end{array}$ & $\begin{array}{c}\text { Factor 2 } \\
\text { CNG }\end{array}$ & $\begin{array}{c}\text { Factor 3 } \\
\text { Diesel }\end{array}$ & $\begin{array}{c}\text { Factor 4 Biomass } \\
\text { burning }\end{array}$ \\
\hline OC1 & 0 & 0 & 0 & 0.99 \\
OC2 & 0.87 & 0 & 0.36 & 0 \\
OC3 & 0.99 & 0.05 & 0.04 & 0 \\
OC4 & 0.92 & 0.33 & 0 & 0.08 \\
EC1 & 0.91 & 0 & 0 & 0 \\
EC2 & 0 & 0.26 & 0.96 & 0 \\
EC3 & 0 & 0.95 & 0.27 & 0 \\
Eigenvalue & 3.46 & 1.7 & 0.94 & 0.82 \\
Variance $(\%)$ & 49.4 & 24.2 & 13.5 & 11.8 \\
\hline
\end{tabular}

At Farm Gate, the contribution from EC fraction is less compared to Amin Bazar. Because, at Farm Gate, only the city vehicles ply on road and during the day-time mostly $80 \%$ of the vehicles are duel-fueled engine (CNG and gasoline). From PCA analysis (Table 3), it has found that source profile is also enriched with diesel exhaust engine. In the Farm Gate site, there are many commercial buildings and private hospitals.
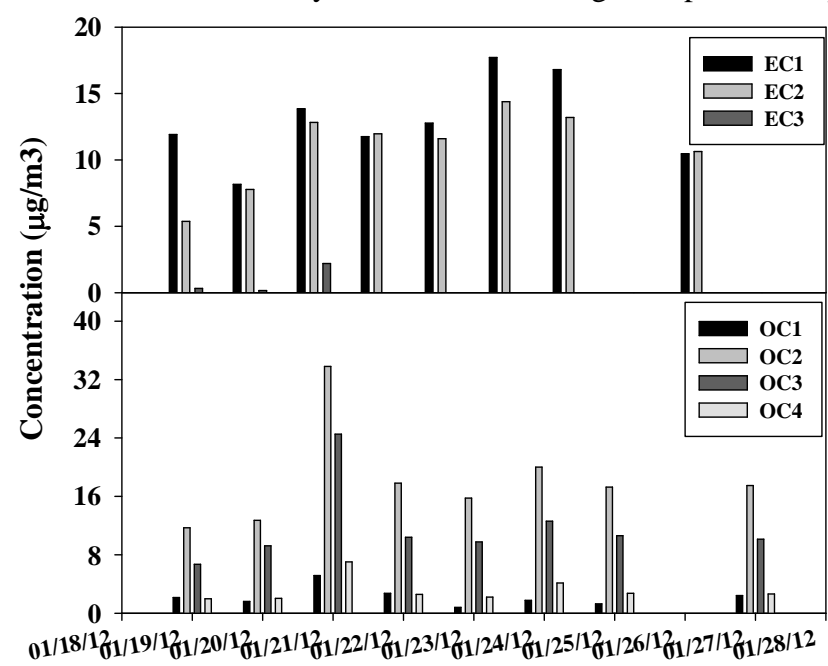

Fig. 3. Fractions of OC1, OC2, OC3, OC4, EC1, EC2 and EC3 in $\mathrm{PM}_{2.5}$ mass at Farm Gate site. 
Hence during power cut, people use diesel generator for the power supply. With the economic growth, the demand for electricity has increased. As a result, authors could find diesel signature in the factor analysis. In order to meet the demand of electricity, there are many quick rental power plants, which run by diesel. On the other hand due to the crisis of CNG fuel, diesel also is used in the vehicles. This may be one of the reasons to get diesel signature in the carbon fraction analysis (Fig. 3).

Table 3. PCA analysis for $\mathbf{P M}_{2.5}$ collected from Farm Gate (CAMS 2).

\begin{tabular}{lccc}
\hline \multirow{2}{*}{ Parameters } & \multicolumn{3}{c}{ Sources } \\
\cline { 2 - 4 } & $\begin{array}{c}\text { Factor 1 } \\
\text { Mixed sources }\end{array}$ & $\begin{array}{c}\text { Factor 2 } \\
\text { Diesel }\end{array}$ & $\begin{array}{c}\text { Factor 3 } \\
\text { Gasoline }\end{array}$ \\
\hline OC1 & 0.95 & 0.02 & 0 \\
OC2 & 0.89 & 0.41 & 0.19 \\
OC3 & 0.92 & 0.33 & 0.14 \\
OC4 & 0.91 & 0.28 & 0.28 \\
EC1 & 0.06 & 0.32 & 0.94 \\
EC2 & 0.17 & 0.88 & 0.44 \\
EC3 & 0.98 & 0 & 0.03 \\
Eigenvalue & 4.88 & 1.64 & 0.32 \\
Variance $(\%)$ & 69.7 & 23.5 & 4.6 \\
\hline
\end{tabular}

It has been found in the previous year (Begum et al. 2011) that the diesel signature in the air was very insignificant (Fig. 4). This is due to the uses of CNG as fuel in vehicles. Due to the economic development, the power crisis has started and to fulfill this demand, quick rental power plants has have been established. These plants run by diesel and get diesel signature in the air (Fig. 3). If it continues, then again the air quality will be deteriorated.
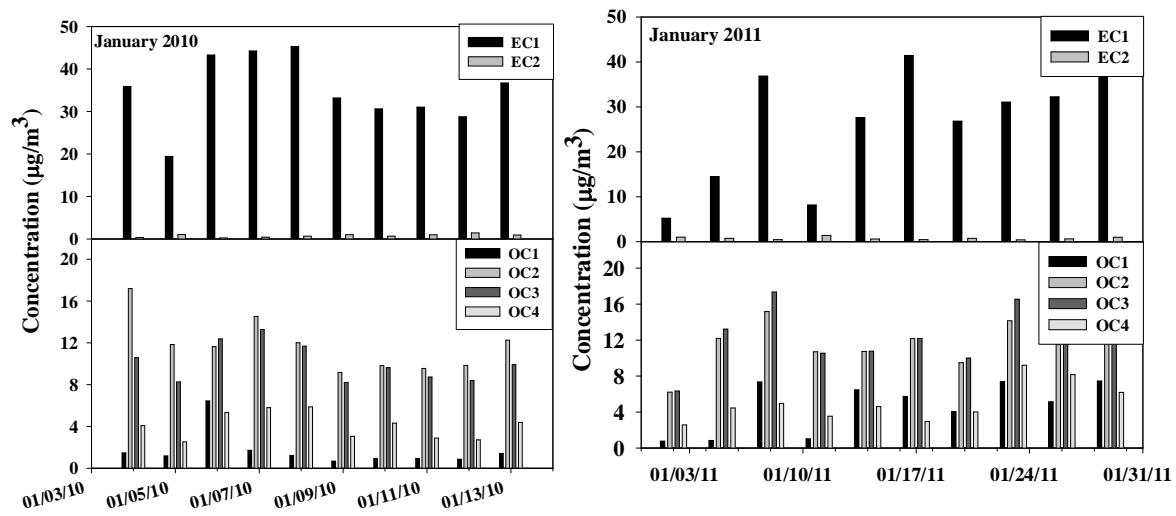

Fig. 4. Fractions of $\mathrm{OC} 1, \mathrm{OC} 2, \mathrm{OC} 3, \mathrm{OC} 4, \mathrm{EC} 1, \mathrm{EC} 2$ and $\mathrm{EC} 3$ in $\mathrm{PM}_{2.5}$ mass in January, 2010 and 2011 at Farm Gate. 


\section{CONCLUSION}

During last couple of years, government has implemented different policies to improve the air quality. But due to the use of diesel in quick rental power plant, the air quality started to deteriorate. EC plays an important role to change the climate due to its light absorbing capacity. Hence, government may think of alternative fuel source to meet the power demand in place of diesel.

\section{REFERENCES}

Baldauf, R. W., D. D. Lane and G. A. Marotz. 2001. Ambient Air Quality Monitoring Network Design for Assessing Human Health Impacts from Exposures to Airborne Contaminants. Environmental Monitoring and Assessment 66: 63-76,

Begum, B. A., S. K. Biswas, E. Kim, P. K. Hopke and M. Khaliquzzaman. 2005. Investigation of sources of atmospheric aerosol at a hot spot area in Dhaka, Bangladesh. J. Air and Waste Management Association 55: 227-240.

Begum, B. A., A. Hossain, G. Saroar, S. K. Biswas, M. Nasiruddin, N. Nahar and P. K. Hopke. 2011. Sources of carboneceous materials in the airborne particulate matter of Dhaka. Asian J. Atmospheric Environment 5: 237-246.

Cao, G., X. Zhang and F. Zheng. 2006. Inventory of black carbon and organic carbon emissions from China. Atmospheric Environment 40: 6516-6527.

Cao, J., F. Wu, J. Chow, S. Lee, Y. Li, S. Chen, Z. An, K. Fung, J. Watson, C. Zho and S. Liu. 2005. Characterization and source apportionment of atmospheric organic and elemental carbon during Fall and Winter of 2003 in Xi'an, China. Atmospheric Chemistry \& Physics 5: 3127-3137.

Dan, M., G. Zhuang, X. Li, H. Tao and Y. Zhuang. 2004. The characteristics of carboneceous species and their sources in $\mathrm{PM}_{2.5}$ in Beijing. Atmospheric Environment 38: 3443-3452.

Hopke, P. K. 1985. Receptor modeling in environmental chemistry. Wiley,New York.

Hopke, P. K., E. S. Gladney, G. E. Gordon, W. H. Zoller and A. G. Jones. 1976. The use of multivariate analysis to identify sources of selected elements in the Boston urban aerosol. Atmospheric Environment. 10: 1015-1025.

Kim, B. M. and R. C. Henry. 2000. Application of SAFER model to the Los Angeles PM $_{10}$ data. Atmospheric Environment 34: 1747-1759.

Li, P., Y. Wang, Y. Li, Z. Wang, H. Zhang, P. Xu and W. Wang. 2010. Characterization of policyclic aromatic hydrocarbons deposition in $\mathrm{PM}_{2.5}$ and cloud/fog water at Mount Taishan (China). Atmospheric Environment 44: 1996-2003.

Lin, J. and H. Tai. 2001. Concentrations and distributions of carbonaceous species in ambient particles in Kaohsiung city, Taiwan. Atmospheric Environment 35: 2627-2636.

Meng, Z., X. Jiang, P. Yan, W. Lin, H. Zhang and Y. Wang. 2007. Characteristics and sources of $\mathrm{PM}_{2.5}$ and carboneceous species during winter in Taiyuan, China. Atospheric Environment 41: 6901-6908.

Pankow, J. 1994. An absorption model of the Gas/Aerosol partitioning involved in the formation of secondary organic aerosol. Atmospheric Environment 28: 189-193.

Ram, K., M. Sarin and P. Hegde. 2008. Atmospheric abundances of primary and secondary carboneceous species at two high-altitude sites in India: Sources and temporal variability. Atmospheric Environment 42: 6785-6796. 
Stern, J., R. Flagan, D. Grosjean and J. Seinfeld. 1987. Aerosol formation and growth in atmospheric aromatic hydrocarbon photooxidation. Environmental Science \& Technology 21: $1224-1231$.

Turpin, B. and J. Huntzicker. 1995. Identification of secondary organic aerosol episodes and quantitation of primary and secondary organic aerosol concentrations during SCAQS. Atmospheric Environment 29: 3527-3544.

Wang, Y., P. Li, H. Li, X. Li and W. Wang. 2010. PAHs distribution in precipitation at Mount Taishan, China. Identification of sources and meteorological influences. Atmospheric Research 95: 1-7.

Wolff, G. T., P. E. Korsog, N. A. Kelly and M. A. Fermam. 1985. Relationships between fine particulte species, gaseous pollutants and meteorological parameters in Detroit 19. Atmospheric Environment 19: 1341-1349.

(Received revised manuscript on 2 November, 2012) 